\title{
Effects of intramuscular alfaxalone-midazolam combination in pigs
}

\author{
Cecilia Vullo ${ }^{1}$, Marina Meligrana ${ }^{2}$, Adolfo Maria Tambella ${ }^{2}$, \\ Angela Palumbo Piccionello ${ }^{2}$, Fabrizio Dini ${ }^{2}$, Giuseppe Catone ${ }^{2}$ \\ University of Camerino, ${ }^{1}$ School of Pharmacy, Camerino (MC), \\ ${ }^{2}$ School of Biosciences and Veterinary Medicine, Matelica (MC), Italy
}

Received January 11, 2019

Accepted April 23, 2019

\begin{abstract}
The aim of this experimental study was to evaluate the sedative and cardiorespiratory effects of alfaxalone and midazolam after intramuscular administration in pigs. Fourteen pigs, weighing 18 to $22 \mathrm{~kg}$, aged between 55 and 70 days, American Society of Anaesthesiologists classification 2 , affected by congenital reducible umbilical hernia, were included in the study. Alfaxalone $(5 \mathrm{mg} / \mathrm{kg})$ and midazolam $(0.5 \mathrm{mg} / \mathrm{kg})$ mixed in the same syringe were administered into the neck muscle. Pain on injection, quality of sedation and time to achieve lateral recumbency were recorded. Heart rate $(\mathrm{HR})$, respiratory frequency $\left(f_{\mathrm{R}}\right)$, and rectal temperature $(\mathrm{RT})$ were recorded at 0 (baseline: before drug administration), 10, 15, and $20 \mathrm{~min}$ after the injection. Oxygen saturation of haemoglobin $\left(\mathrm{SpO}_{2}\right)$, arterial blood $\mathrm{pH}$, arterial oxygen $\left(\mathrm{PaO}_{2}\right)$ and carbon dioxide $\left(\mathrm{PaCO}_{2}\right)$ tensions and bicarbonate concentration $\left(\mathrm{HCO}_{3}-\right)$ were recorded at 10, 15, and $20 \mathrm{~min}$ after injection. Continuous data were analysed using a repeated-measure analysis of variance (ANOVA) and a $P$-value $<0.05$ was considered significant. Ten animals out of fourteen showed no pain on injection, whereas the remaining four exhibited mild pain. The time from the end of injection to lateral recumbency was $266 \pm 40 \mathrm{~s}$. The quality of sedation ranged between good to very good. No significant changes in the variables monitored were observed between the time points. In conclusion, the intramuscular administration of alfaxalone and midazolam in pigs at the doses used induced reliable and fast sedation, without pain on injection and moderate respiratory effects.
\end{abstract}

Experimental study, swine model, sedation

Pigs are often used as experimental animal models in medical research because their organism has major similarities to that of humans (Huter et al. 2004; Gupta et al. 2005). Therefore, it is necessary to study new and effective anaesthetic protocols in order to preserve animal welfare in medical investigation (Calzetta et al. 2014). Physical restraint is difficult in pigs and a source of stress; furthermore, placement of an intravenous (i.v.) catheter is challenging if the animal is not properly sedated (Heinonen et al. 2009; Lee and Kim 2012; Malavasi 2015). Therefore, sedatives are generally administered intramuscularly (i.m.) in pigs (Nishimura et al. 1992; Henrikson et al. 1995). Ideally, the sedative(s) administered should provide a reliable and fast sedation, an adequate analgesia and muscle relaxation, should be painless at injection and produce minimal cardiorespiratory effects (De Monte et al. 2015).

Several drugs have been combined and investigated in pigs for i.m. administration: ketamine, alfaxalone, tiletamine-zolazepam, tranquillizers (such as azaperone) and a2-agonists (Sakaguchi et al. 1995; Hall et al. 2001; Keats 2003; Kim et al. 2007; Ajadi et al. 2008; Bettschart-Wolfensberger et al. 2013; Santos González et al. 2013; Santos et al. 2016).

Alfaxalone is a potent neuroactive steroid anaesthetic agent that activates the gammaaminobutyric acid (GABA) ${ }_{A}$ receptor (Lan and Gee 1994). In pigs, alfaxalone produces sedation or induces general anaesthesia depending on the dose, and it can be administered both i.m and i.v. (Keats 2003; Bigby et al. 2017; Santos González et al. 2013). 
Therefore, it could be a good alternative to ketamine or tiletamine-zolazepam previously used in this species (Nishimura et al. 1992; Sakaguchi et al. 1995; Sweitzer et al. 1997; Kim et al. 2007; Ajadi et al. 2008; Heinonen et al. 2009; Lee and Kim 2012; Bettschart-Wolfensberger et al. 2013; De Monte et al. 2015; Santos et al. 2016) that can often cause a rough and stressful recovery (Malavasi 2015).

Midazolam is a benzodiazepine that, acting on the $\mathrm{GABA}_{\mathrm{A}}$ receptor, causes muscle relaxation and sedation with minimal cardiorespiratory effects in pigs (Smith et al. 1991; Bustamante and Valverde 1997). In contrast to diazepam, midazolam is hydrosoluble and is well absorbed after an i.m. injection (Quandt 2013). Even when administered on its own, i.m. midazolam produces sedation, facilitating physical restraint in pigs (Bustamante and Valverde 1997).

The purpose of this study was to investigate the effect of i.m. administration of alfaxalone and midazolam in pigs. We hypothesize that alfaxalone and midazolam will not cause pain on injection and will produce effective and fast sedation with minimal cardiorespiratory effects in pigs.

\section{Materials and Methods}

Fourteen healthy mixed-breed male pigs (Large White $\times$ Duroc) weighing 18 to $22 \mathrm{~kg}$, aged between 55 and 70 days and affected by uncomplicated reducible congenital umbilical hernia were included in the study. The pigs were involved in another experimental study in which herniorrhaphy was performed inserting a new absorbable prosthetic mesh $\left(\mathrm{BARD}^{\mathbb{R}}\right.$, Italy) under general anaesthesia. The animals were handled according to European and national regulations on the protection of experimental animals (Directive 2010/63/UE and RD 53/2013) and the study was approved by the Italian Ministry of Health (authorization number 403/2016).

The animals were housed in the Large Animal Facility of the Camerino University, Italy. After an acclimation period of at least $72 \mathrm{~h}$, the pigs underwent a routine pre-anaesthetic physical examination in order to assess their health status which was classified as 2 according to the American Society of Anaesthesiologists. Exclusion criteria were: incarcerated or strangulated hernia, local inflammation or infection due to trauma, presence of systemic symptoms (i.e. cough, nasal discharge, hyperthermia). Food was withheld for $12 \mathrm{~h}$ and water for $30 \mathrm{~min}$ prior to anaesthesia.

Before the i.m. injection, baseline heart rate (HR), respiratory frequency $\left(f_{\mathrm{R}}\right)$ and rectal temperature (RT) were recorded (Table 1). The HR was measured by auscultation using a stethoscope, $f_{\mathrm{R}}$ was measured by observation of thoracic excursions, RT was recorded using a digital thermometer. Alfaxalone $\left(5 \mathrm{mg} / \mathrm{kg}\right.$, Alfaxan ${ }^{\circledR}$, Dechra, Italy) and midazolam $\left(0.5 \mathrm{mg} / \mathrm{kg}\right.$, Midazolam ${ }^{\circledR}$, Ibi, Italy) were mixed in the same syringe, and $0.9 \%$ sodium chloride was added as necessary to reach a total volume of $14 \mathrm{ml}$. The mixture was administered i.m. into the neck behind the base of the ear and in front of the angle of the shoulder using a 18 gauge, $3.75 \mathrm{~cm}$ long hypodermic needle connected to a line extension $\left(75 \mathrm{~cm}, 1.3 \mathrm{ml}\right.$ volume, Sidam Medical Device ${ }^{\circledR}$, Italy). The extension was previously filled with the sedative solution and, to avoid leaving sedative residues inside, it was immediately flushed with $1.5 \mathrm{ml}$ of sterile water for injection. All the injections were performed over a period of $20 \mathrm{~s}$ without physical restraint.

Pain on injection was scored using a simple descriptive scale modified from that of Michou et al. (2012) and Santos et al. (2016): score $0=$ no pain (the animal is quiet and indifferent to the injection); score $1=$ mild pain (movement of tail and turning of head towards injection site); score $2=$ moderate pain (light grunts and attempts to remove needle); and score 3 = severe pain (strong vocalization and attempts to escape, requiring vigorous physical restraint). Time from end of injection to lateral recumbency was also recorded.

At 10, 15 and $20 \mathrm{~min}$ from i.m. administration $\mathrm{HR}, f_{\mathrm{R}}$, RT were recorded. Further, the pulsatile oxygen saturation of haemoglobin $\left(\mathrm{SpO}_{2}\right.$; Nellcor ${ }^{\mathrm{TM}}$ Portable $\mathrm{SpO}_{2}$, Covidien) was recorded applying the probe to the tail. At the same time points, arterial blood samples were collected anaerobically from the femoral artery and immediately analysed (i-STAT System, Abbot) in order to obtain $\mathrm{pH}$, arterial oxygen $\left(\mathrm{PaO}_{2}\right)$ and carbon dioxide $\left(\mathrm{PaCO}_{2}\right)$ tensions and bicarbonate concentration $\left(\mathrm{HCO}_{3}^{-}\right)$.

Quality of sedation was scored using a 4-point simple descriptive scale modified from Santos et al. (2016) $20 \mathrm{~min}$ after drug administration: score $0=$ no apparent sedation, pig standing and able to walk; score $1=$ pig is quieter but it stands and is reactive to manipulation; score 2 = pig in sternal recumbency and unable to walk; score 3 = pig in lateral recumbency and not reactive to manipulation.

All of the variables and scores were assessed and recorded by the same investigator.

Shapiro-Wilk test was used to confirm that the data were normally distributed. Subsequently, values of $\mathrm{HR}, f_{\mathrm{R}}$, RT, $\mathrm{SpO}_{2}, \mathrm{pH}, \mathrm{PaO}_{2}, \mathrm{PaCO}_{2}$ and $\mathrm{HCO}_{3}^{-}$were analysed using a repeated-measure analysis of variance (ANOVA). A $P$-value $<0.05$ was considered significant. The data are reported as the mean \pm standard deviation (SD).

Pain at injection and sedation score are reported as median (range). 


\section{Results}

The sedative solution was administered without any problem in all the pigs. Pain at injection was scored 0: ten animals showed no pain on drug injection (score 0) and four mild pain (score 1). After 20 min from injection, the quality of sedation was scored 3: score 2 in two pigs and score 3 in the remaining twelve. Time from the end of injection to lateral recumbency was $266 \pm 40 \mathrm{~s}$. There were no significant differences in HR, $f_{\mathrm{R}}$, $\mathrm{RT}$ and $\mathrm{SpO} 2$ between the time points (Table 1). Arterial blood $\mathrm{pH}, \mathrm{PaCO}_{2}$ tensions and $\mathrm{HCO}_{3}$ - did not change significantly over time, while $\mathrm{PaO}_{2}$ showed a mild decrease (Table 2). Just before and during recumbency, none of the animals presented excess salivation or apnoea. No pigs showed vocalization, limb paddling or any other local side effect related to the volume injected. Anaesthesia was deepened using isoflurane (Isoflurane Vet $^{\mathbb{R}}$, Merial, Italy) administered via face mask. An i.v. catheter (Terumo ${ }^{\circledR}$, Demas, Italy) was inserted into the auricular vein and, once the mandibular reflex was lost, the endotracheal intubation was performed. Anaesthesia was maintained with isoflurane vaporized in oxygen.

Table 1. Variables measured in pigs at baseline and at 10,15 and $20 \mathrm{~min}$ following alfaxalone-midazolam administration.

\begin{tabular}{lcccc}
\hline Time & 0 min & $10 \mathrm{~min}$ & $15 \mathrm{~min}$ & $20 \mathrm{~min}$ \\
\hline $\mathrm{HR}$ & $174.4 \pm 8.6$ & $172.5 \pm 10.2$ & $174.5 \pm 7.4$ & $178 \pm 9.0$ \\
$f_{\mathrm{R}}$ & $48.5 \pm 8.7$ & $46.5 \pm 10.2$ & $47.5 \pm 12.3$ & $46 \pm 10.0$ \\
$\mathrm{RT}$ & $39.6 \pm 0.1$ & $39.4 \pm 0.2$ & $38.9 \pm 0.1$ & $38.9 \pm 0.1$ \\
$\mathrm{SpO}_{2}$ & $\mathrm{NA}$ & $94 \pm 3.3$ & $94.2 \pm 3.0$ & $94.5 \pm 2.2$ \\
\hline
\end{tabular}

$\mathrm{HR}$ : heart rate; $f_{\mathrm{R}}$ : respiratory rate; $\mathrm{RT}$ : rectal temperature; $\mathrm{SpO}_{2}$ : oxygen saturation of haemoglobin; NA: not available. Values are given as the mean \pm standard deviation. No significant differences in $\mathrm{HR}, f_{\mathrm{R}}, \mathrm{RT}$ and $\mathrm{SpO}$ between time points $(P>0.05)$.

Table 2. Arterial blood gas indices in pigs at 10, 15 and 20 min following alfaxalone-midazolam administration.

\begin{tabular}{lccr}
\hline Time & $10 \mathrm{~min}$ & $15 \mathrm{~min}$ & \multicolumn{1}{c}{$20 \mathrm{~min}$} \\
\hline $\mathrm{pH}$ & $7.4 \pm 0.3$ & $7.4 \pm 0.2$ & $7.4 \pm 0.2$ \\
$\mathrm{PaO}_{2}(\mathrm{mmHg})$ & $72.2 \pm 11.2$ & $75.5 \pm 12.3$ & $73.5 \pm 8.3$ \\
$\mathrm{PaCO}_{2}(\mathrm{mmHg})$ & $46.4 \pm 0.18$ & $48.2 \pm 1.1$ & $48.5 \pm 2.1$ \\
$\mathrm{HCO}_{3}^{-}(\mathrm{mmol} / \mathrm{l})$ & $34.2 \pm 3.3$ & $32.1 \pm 2.9$ & $33.7 \pm 2.2$ \\
\hline
\end{tabular}

$\mathrm{pH}$ : hydrogen ion concentration; $\mathrm{PaO}_{2}$ : arterial oxygen; $\mathrm{PaCO}_{2}$ : arterial carbon dioxide tensions; $\mathrm{HCO}_{3}^{-}:$bicarbonate concentration. Values are given as the mean \pm standard deviation. No significant differences in $\mathrm{HR}, f_{\mathrm{R}}, \mathrm{RT}$ and $\mathrm{SpO} 2$ between the time points $(P>0.05)$.

In the present study, the im administration of alfaxalone-milazolam produced a reliable sedation with no pain on injection and moderate respiratory effects, as similarly reported in another study (Bigby et al. 2017).

Previous studies investigated the use of midazolam as a sedative in pigs but with conflicting results. After i.m. administration of midazolam $(0.1 \mathrm{mg} / \mathrm{kg})$, Smith et al. (1991) described a stable cardiac function with no modifications of blood gases and $\mathrm{pH}$ compared to non-sedated pigs, despite a significant decrease in $\mathrm{HR}$ and $f_{\mathrm{R}}$. The authors concluded that midazolam is an effective swine sedative.

Bustamante and Valverde (1997) administered i.m. 0.25, 0.5 and $1 \mathrm{mg} / \mathrm{kg}$ midazolam to determine the most effective sedative dose for handling pigs. They concluded that 
the dose of $0.5 \mathrm{mg} / \mathrm{kg}$ i.m. of midazolam was the most suitable for sedation in pigs with minimal cardiorespiratory changes. Similarly to our results, no significant decrease in HR and $f_{\mathrm{R}}$ was documented.

Alfaxalone has been previously used in pigs as a pre-anaesthetic medication, to induce and / or maintain general anaesthesia, either alone or in combination with other drugs (Quandt 2013; Santos González et al. 2013; Santos et al. 2016; Bigby et al. 2017). When administered on its own in non-sedated pigs, alfaxalone is effective but causes muscular twitching (Keates 2003; Santos González et al. 2013; Bigby et al. 2017). Similar results have also been found in other animal species (Keates et al. 2012; Warne et al. 2015; Tamura et al. 2015). Therefore, alfaxalone is often used in combination with other drugs.

The i.m. administration of alfaxalone $(5 \mathrm{mg} / \mathrm{kg})$ and diazepam $(0.5 \mathrm{mg} / \mathrm{kg})$ in six pigs was investigated by Santos González et al. (2013). The authors reported that the administration resulted in a rapid onset of lateral recumbency $(232 \pm 45 \mathrm{~s})$ and in a fair to smooth quality of sedation. One animal showed mild pain during drug injection. In our study, the time to achieve recumbency was longer (266 $\pm 40 \mathrm{~s}$ ) compared to that reported by Santos González et al. (2013). This variation might have been due to the different site of injection chosen in this study (the neck muscle vs the lumbar muscle).

Differently from midazolam, diazepam has a $\mathrm{pH}$ of $6.6-6.9$, it is poorly water soluble and it is commercialised as a solution containing benzoic acid, ethanol $96 \%$, sodium benzoate, benzyl alcohol and propylene glycol. This may cause pain after i.m. and i.v. diazepam administration. Further, the poor hydrosolubility and the excipient contained in the solution can cause unpredictable systemic absorption after i.m. administration (Meyer and Fish 2008; Rankin 2015). Therefore, the use of midazolam (commercialised as a hydrosoluble solution, with $\mathrm{pH}<4$, containing sodium chloride, $10 \%$ hydrochloric acid, sodium hydroxide) can probably explain the lack of pain and the more profound sedative effect recorded in our study.

Further studies are needed in order to assess the quality of the recovery following the alfaxalone-midazolam administration, since in our work the animals were involved in another experimental research which required the utilization of additional drugs for the induction of the general anaesthesia.

Moreover, the commercially available formulation of alfaxalone is characterized by a low concentration, thus, the resultant volumes of injection limit its i.m. use to small pigs.

Since neither alfaxalone nor midazolam produce any significant analgesia, the use of analgesics should be considered to treat pain prior to the procedural training.

The results of this study suggest that the i.m. administration of alfaxalone in combination with midazolam at the dose used induces good to very good sedation and fast lateral recumbency without significant differences in $\mathrm{HR}, f_{\mathrm{R}}$ or $\mathrm{RT}$ compared to baseline values. Moreover, arterial blood $\mathrm{pH}, \mathrm{PaCO}_{2}$ tensions and $\mathrm{HCO}_{3}{ }^{-}$remained within the physiological range, whereas $\mathrm{PaO}_{2}$ showed a mild decrease.

Although neither alfaxalone nor midazolam are allowed in pigs, their use should be considered in medical training and research, since their combination, at the doses used, resulted in reliable and satisfactory restraint in pigs, which could result in a useful handling protocol. Further studies evaluating the recovery time are required to assess the differences between the combination used in this study and other combinations, such as ketaminebenzodiazepine or tiletamine-zolazepam which can also be administered i.m. to induce anaesthesia in pigs.

\section{Conflict of Interest}

The authors declare no conflicts of interest. 


\section{References}

Ajadi RA, Smith OF, Makinde AFM, Adeleye OE 2008: Increasing ketamine dose enhances the anaesthetic properties of ketamine-xylazine-midazolam combination in growing pigs. J S Afr Vet Assoc 79: 205-207

Bettschart-Wolfensberger R, Stauffer S, Hässig M, Flaherty D, Ringer SK 2013: Racemic ketamine in comparison to S-ketamine in combination with azaperone and butorphanol for castration of pigs. Schweiz Arch Tierheilkd 155: $669-675$

Bigby SE, Carter JE, Bauquier S, Carter JE 2017: The use of alfaxalone for premedication, induction and maintenance of anaesthesia in pigs: a pilot study. Vet Anaesth Analg 44: 905-909

Bustamante R and Valverde A 1997: Determination of sedative dose and influence of droperidol and midazolam on cardiovascular function in pigs. Can J Vet Res 61: 246-250

Calzetta L, Rossi P, Bove P, Alfonsi P, Bonizzi L, Roncada P, Bernardini R, Ricciardi E, Montuori M, Pistocchini E, Mauti P, Mattei M 2014: A novel and effective balanced intravenous-inhalant anaesthetic protocol in swine by using unrestricted drugs. Exp Anim 63: 423-433

De Monte V, Staffieri F, Di Meo A, Vannucci J, Bufalari A 2015: Comparison of ketamine-dexmedetomidinemethadone and tiletamine-zolazepam-methadone combinations for short-term anaesthesia in domestic pigs. Vet J 205: 364-368

Gupta S, Westfall T, Lechner A, Knuepfer MM 2005: Teaching principles of cardiovascular function in a medical student laboratory. Adv Physiol Ed 29: 118-127

Hall LW, Clarke KW, Trim CM 2001: Anaesthesia of the pig. In Hall LW, Clarke KW, Trim CM (Eds): Veterinary Anesthesia. 10 $0^{\text {th }}$ edn. WB Sauders, London, pp. 367-383

Heinonen ML, Raekallio MR, Oliviero C Ahokas S, Peltoniemi OA 2009: Comparison of azaperone-detomidinebutorphanol-ketamine and azaperone-tiletamine-zolazepam for anaesthesia in piglets. Vet Anaesth Analg 36: 151-157

Henrikson H, Jensen-Waern M, Nyman G 1995: Anaesthetics for general anaesthesia in growing pigs. Acta Vet Scand 36: 401-411

Huter L, Schwarzkopf K, Preussler NP, Gaser E, Schubert H, Karzai W, Schreiber T 2004: Measuring cardiac output in one-lung ventilation: a comparison of pulmonary artery and trans-pulmonary aortic measurements in pigs. J Cardiothor Vasc Anaesth 18: 190-193

Keates H, 2003: Induction of anesthesia in pigs using a new alphaxalone formulation. Vet Rec 153: 627-628

Keates HL, van Eps AW, Pearson MR, 2012: Alfaxalone compared with ketamine for induction of anaesthesia in horses following xilazine and guaifenesin. Vet Anaesth Analg 39: 591-598

Kim MJ, Park CS, Jun MH, Kim MC 2007: Antagonistic effects of yohimbine in pigs anaesthetised with tiletamine/zolazepam and xylazine. Vet Rec 161: 620-624

Lan NC, Gee KW 1994: Neuroactive steroid actions at the GABAA receptor. Horm Behav 28: 537-544

Lee JY, Kim MC 2012: Anesthesia of growing pigs with tiletamine-zolazepam and reversal with flumazenil. J Vet Med Sci 74: 335-339

Malavasi LM 2015: Swine. In: Grimm KA, Lamont LA, Tranquilli WJ, Greene SA, Robertson SA (Eds): Lumb and Jones' Veterinary Anesthesia and Analgesia. $5^{\text {th }}$ edn. John Wiley \& Sons, Inc, Oxford, pp. 928-940

Meyer RE, Fish RE 2008: Pharmacology of injectable anesthetics, sedatives, and tranquilizers. In: Fish RE, Danneman P, Brown M, Karas A (Eds): Anesthesia and Analgesia in Laboratory Animals. $2^{\text {nd }}$ edn, Elsevier Inc, London, pp. 44-47

Michou JN, Leece EA, Brearley JC 2012: Comparison of pain on injection during induction of anaesthesia with alfaxalone and two formulations of propofol in dog. Vet Anaesth Analg 39: 275-281

Nishimura R, Sakaguchi M, Mochizuki M, Sasaki N, Takahashi H, Tamura H, Takeuchi A 1992: A balanced anaesthesia with a combination of xylazine, ketamine and butorphanol and its antagonism by yohimbine in pigs. J Vet Med Sci 54: 615-620

Quandt J 2013: Analagesia, anesthesia, and chemical restraint in the emergent small animal patient. Vet Clin North Am Small Anim Pract 43: 941-953

Rankin DC 2015: Sedatives and Tranquilizers. In: Grimm KA, Lamont LA, Tranquilli WJ, Greene SA, Robertson SA (Eds): Lumb and Jones' Veterinary Anesthesia and Analgesia. $5^{\text {th }}$ edn. John Wiley \& Sons, Inc, Oxford, pp: $196-206$

Sakaguchi M, Nishimura R, Sasaki N, Ishiguro T, Tamura H, Takeuchi A 1995: Chemical restraint by medetomidine-ketamine and its cardiopulmonary effects in pigs. Zentralbl Veterinärmed. Reihe A 42: 293-299

Santos M, Bertrán de Lis BT, Tendillo FJ 2016: Effects of intramuscular dexmedetomidine in combination with ketamine or alfaxalone in swine. Vet Anaesth Analg 43: 81-85

Santos González M, Bertrán de Lis BT, Tendillo Cortijo FJ 2013: Effects of intramuscular alfaxalone alone or in combination with diazepam in swine. Vet Anaesth Analg 40: 399-402

Smith AC, Zellner JL, Spinale FG, Swindle MM 1991: Sedative and cardiovascular effects of midazolam in swine. Lab Anim Sci 41: 157-161

Sweitzer RA, Ghneim GS, Gardner IA, van Vuren D, Gonzales BJ, Boyce WM 1997: Immobilization and physiological parameters associated with chemical restraint of wild pigs with Telazol $^{\circledR}$ and xylazine hydrochloride. J Wildl Dis 33: 198-205 
Tamura J, Ishizuka T, Fukui S, Oyama N, Kawase K, Miyoshi K, Sano T, Pasloske K, Yamashita K 2015: The pharmacological effects of the anesthetic alfaxalone after intramuscular administration to dogs. J Vet Med Sci 77: $289-296$

Warne LN, Beths T, Whittem T, Carter JE, Bauquier SH 2015: A review of the pharmacology and clinical application of alfaxalone in cats. Vet J 203: 141-148 